\title{
Shivering management during therapeutic hypothermia in patients with traumatic brain injury: protocol from the Eurotherm 3235 trial
}

\author{
Jonathan KJ Rhodes ${ }^{*}$, H Louise Sinclair, Claire G Battison, Bridget Harris, Peter JD Andrews \\ From Targeted Temperature Management (TTM 2014) \\ Berlin, Germany. 6-7 November 2014
}

Effective hypothermia in critical care requires a strategy to prevent and manage shivering. Core body temperature in mammals is highly regulated [1]. Hypothermia leads to the activation of measures to counteract this, reducing heat loss through vasoconstriction and increasing heat generation through increased metabolism and shivering.

Shivering resists the reduction in core temperature but also increases physiological stresses, including an increase in oxygen demand, catecholamine release and hypertension. It also can appear distressing, may be confused with seizure activity and generally results in monitoring being more difficult.

In the Eurotherm3235 trial [2], the prevention of shivering required that patients were prepared for hypothermia appropriately, that shivering was detected early and that a plan to treat shivering was followed should it be detected. Patients were sedated with an opiate, propofol and/or midazolam because anesthetic agents have been shown to reduce the core temperature set point for shivering. Regular paracetamol was also prescribed as this reduces the hypothalamic temperature set point. The hands and feet of patients were covered with towels, which in addition to reducing the risk of thermal burns has been shown to suppress shivering [3]. During hypothermia, patients were observed closely for signs of shivering, particularly in the jaw, neck and trunk as these areas area the earliest to show signs of shivering [4].

On detection of possible shivering, seizures and inadequate sedation were excluded as causes of muscle movements. Specific interventions included active skin counter-warming with forced air convection as mean skin temperature contributes around $20 \%$ to the control of autonomic cold defenses, such as vasoconstriction and shivering, and $50 \%$ to thermal comfort [5], or the use of pethidine and the 2-agonist clonidine, each associated with significant anti-shivering effects [6].

\section{Acknowledgements}

The authors were supported by awards from National Health Research Scotland and the Heath Technology Assessment Program of the National Institute for Health Research, UK. JKJR and PJDA have received honorariums from C. R. BARD for lecturing. C. R. BARD had no input into the topics covered in this abstract.

Published: 24 June 2015

\section{References}

1. Sessler DI: Defeating normal thermoregulatory defenses: induction of therapeutic hypothermia. Stroke 2009, 40(11):e614-e621.

2. Andrews PJ, Sinclair HL, Battison CG, Polderman KH, Citerio G, Mascia L, et al: European society of intensive care medicine study of therapeutic hypothermia (32-35 degrees C) for intracranial pressure reduction after traumatic brain injury (the Eurotherm3235Trial). Trials 2011, 12:8-12.

3. Sweney MT, Sigg DC, Tahvildari S, laizzo PA: Shiver suppression using focal hand warming in unanesthetized normal subjects. Anesthesiology 2001, 95(5):1089-1095.

4. Tikuisis $P$, Bell DG, Jacobs I: Shivering onset, metabolic response, and convective heat transfer during cold air exposure. J Appl Physiol 1991, 70(5):1996-2002.

5. Pitoni S, Sinclair HL, Andrews PJ: Aspects of thermoregulation physiology. Curr Opin Crit Care 2011, 17(2):115-121.

6. Park SM, Mangat HS, Berger K, Rosengart AJ: Efficacy spectrum of antishivering medications: meta-analysis of randomized controlled trials. Crit Care Med 2012, 40(11):3070-3082.

doi:10.1186/1471-227X-15-S1-A7

Cite this article as: Rhodes et al: Shivering management during therapeutic hypothermia in patients with traumatic brain injury: protocol from the Eurotherm3235 trial. BMC Emergency Medicine 2015 15(Suppl 1):A7. 